\title{
Pharmacological and Nonpharmacological Factors Influencing Hypothalamic-Pituitary-Adrenocortical Axis Reactivity in Acutely Depressed Psychiatric In-patients, Measured by the Dex-CRH Test
}

\author{
HE Künzel',2, EB Binder*,1,2, T Nickel', M Ising', B Fuchs', M Majer', A Pfennig', G Ernst', N Kern', \\ DA Schmid', M Uhr', F Holsboer' and S Modell' \\ 'Department of Psychiatry, Max Planck Institute of Psychiatry, Munich, Germany
}

\begin{abstract}
The most consistent biological findings in patients with depression are abnormalities in the hypothalamic-pituitary-adrenal (HPA)-axis, which can be measured using the combined dexamethasone-suppression/CRH-stimulation (Dex- $\mathrm{CRH}$ ) test. The reactivity of the HPAaxis in this test, however, ranges over several orders of magnitude in depressed patients with comparable severity of symptoms. In this present study, we investigate which factors influence the magnitude of the response in the Dex-CRH test in 235 acutely depressed inpatients. We first examined the effects of common confounders shown to influence the HPA-axis, such as caffeine and nicotine consumption, acute stressors during the test, weight, gender, and age. Of all these variables, only female sex and nicotine consumption were positively correlated with the cortisol or ACTH response, respectively. As for the effects of psychopharmacological treatment, only the intake of carbamazepine and the fact of having relapsed under an established pharmacotherapy significantly increased the response in the Dex-CRH test, whereas the presence or absence of antidepressant treatment, the type of antidepressant treatment, or the number of ineffective antidepressant treatment trials during the index episode up to admission did not have any effect. We also found a positive correlation of the number of previous episodes, the overall HAM-D score and the severity of somatic/vegetative symptoms with the results in the Dex-CRH test. These results underline that in depressed patients this test is not majorly influenced by disease-unrelated factors. In addition, current antidepressant treatment does not appear to affect test outcome in the absence of clinical response. The influence of the number of previous episodes and relapse under pharmacotherapy suggests that HPA-axis reactivity may be altered by repetitive states of hypercortisolemia or continuous antidepressant treatment. Finally, more severe vegetative symptoms are associated with an enhanced HPA-axis activity.

Neuropsychopharmacology (2003) 28, 2 I69-2178, advance online publication, 20 August 2003; doi: I 0.1 038/sj.npp. 1300280
\end{abstract}

Keywords: depression; HPA-axis; Dex-CRH test; cortisol; $\mathrm{ACTH}$; neuroendocrine

\section{INTRODUCTION}

A series of clinical and preclinical data indicate that a hyperactivity of the hypothalamic-pituitary-adrenal (HPA)-axis, especially of the hypothalamic tridecapeptide corticotropin-releasing hormone (CRH), may underlie depressive symptomatology and may be an antidepressant target (Holsboer, 1999; Mitchell, 1998). Depression-associated symptoms such as decreased food intake, reduced social interaction, increased locomotor activity, and anxiety

\footnotetext{
*Correspondence: Dr EB Binder, Department of Psychiatry, Max Planck Institute of Psychiatry, Kraepelinstr. 2-10, D-80804 Munich, Germany, Tel: + +498930622 608, Fax: + +498930622 605, E-mail: binder@mpipsykl.mpg.de

These authors contributed equally to the manuscript.

Received 07 April 2003; revised 19 May 2003; accepted 10 June 2003 Online publication: 25 June 2003 at http://www.acnp.org/citations/ Npp06250303 I 54/default.pdf
}

can be provoked by central application of CRH in monkeys and rodents (Kalin et al, 1983; Owens and Nemeroff, 1991; Holsboer, 1999). In depressed patients, hyperactivity of the HPA system is one of the most robust neurobiological findings. An increased number of CRH mRNA expressing neurons in the hypothalamus and a reduced CRH receptor binding capacity in the frontal cortex in post-mortem studies as well as increased $\mathrm{CRH}$ concentration in cerebrospinal fluid were reported for patients with depression (Nemeroff et al, 1984, 1988; Raadsheer et al, 1994). These data add to studies showing blunted adrenocorticotropic hormone (ACTH) response to intravenous CRH in depressed patients, which was interpreted to reflect increased hypothalamic CRH secretion stimulating pituitary corticotrophs (Holsboer et al, 1984; Gold et al, 1986). In addition, there appears to be an altered feedback regulation of the HPA-axis via the glucocorticoid receptors in these patients, which is reflected by a basal hypercortisolemia 
(Halbreich et al, 1985) and cortisol escape from dexamethasone suppression (Stokes et al, 1984) as well as an increased ACTH and cortisol release in the combined dexamethasone-suppression/CRH-stimulation test (Dex$\mathrm{CRH}$ test) (Heuser et al, 1994b; von Bardeleben and Holsboer, 1991; Modell et al, 1997). So far, the Dex-CRH test appears to be the most sensitive tool to detect depression-related changes in the HPA-axis (Heuser et al, 1994b). Changes in HPA-axis reactivity in this test are correlated with changes in depressive symptomatology. Normalization of the Dex-CRH test was shown to anticipate or parallel response to antidepressant treatment (Holsboer et al, 1987; Heuser et al, 1996; Holsboer-Trachsler et al, 1991; Nickel et al, 2003), and hyperactivity of the HPA-axis in the Dex-CRH test in remitted patient may predict relapse within the next 6 months (Zobel et al, 1999, 2001).

Even though over $80 \%$ of depressed patients are reported to display an increased response in this test (Heuser et al, 1994b), cortisol and ACTH responses in acutely depressed patients actually show a broad range within (Heuser et al, 1994b) and between studies (mean peak cortisol value reported in Heuser et al (1994b) is about $200 \mathrm{ng} / \mathrm{ml}$, while Zobel et al (2001), Hatzinger et al (2002), and Rybakowski and Twardowska (1999) report mean peak cortisol values from about 20 to $60 \mathrm{ng} / \mathrm{ml}$ ). In our own sample, peak cortisol values range from 3.9 to $332.4 \mathrm{ng} / \mathrm{ml}$ (mean/ $\mathrm{SD}=62.6 / 55.3$ ). These values are still significantly higher than the ones reported for healthy controls in Holsboer et al (1995) (mean peak cortisol value $27.3 \mathrm{ng} / \mathrm{ml}(\mathrm{SD}=17.4)$, $p=0.005$ for a two-sided $t$-test).

The question we wanted to address in this study is which kind of factors may be responsible for this wide range of responses and what might distinguish patients with a highly dysregulated HPA-axis from those who display only a marginally hyperactive stress hormone system.

Only a handful of studies have investigated the factors influencing the magnitude of the ACTH and cortisol response in the Dex-CRH test. So far effects of age, sex, diagnosis (bipolar vs unipolar), and severity of psychopathology and of medication have been reported (Heuser et al, 1994b; Rybakowski and Twardowska, 1999; Zobel et al, 2001). Sample sizes in these studies, however, ranged only from 40 to a maximum of 96 patients. We analyzed potential factors influencing the Dex-CRH test at admission in a sample of 235 in-patients with depressive disorders including unipolar depression (single or recurrent episode, with or without psychotic features), dysthymia, and bipolar disorder. First, the effects of general factors such as gender, age, nicotine and caffeine consumption, body weight, and number of attempts needed to place the venous catheter for the test were analyzed. In a second step, factors associated with the affective disorder itself or its treatment were investigated. These included differences in disease severity, diagnostic subtypes, disease and family history, and psychopharmacological treatment.

\section{METHODS}

\section{Subjects}

A total of 235 patients admitted to our psychiatric hospital for treatment of a depressive disorder presenting with a single or recurrent major depressive episode, dysthymia, or bipolar disorder were included in the study. The data of 67 patients were already included in Zobel et al (2001) and of 41 patients in Nickel et al (2003). Comorbid anxiety, somatoform or substance abuse, eating or personality disorders were recorded but did not present an exclusion criterion. Overall, patients with psychiatric comorbidity represented $21.2 \%$ of the subjects. Distribution of primary DSM IV diagnoses and psychiatric comorbidities as well as other demographic data are listed in Table 1. Depressive disorders due to a medical or neurological condition were an exclusion criterion. The study has been approved by the local ethical committee. Written informed consent was obtained from all subjects.

\section{Study Design}

Patient characteristics. Patients were included in the study within 1-10 days of admission and the diagnosis was ascertained by trained psychiatrists according to the DSM IV. Disease and history was recorded by directly questioning the patients and from medical records including age at onset, number of previous episodes (manic and depressive), and duration of the index episode. Family history was ascertained using an unstructured interview, and patients were classified as having a positive family history when at least one of the first- or second-grade relatives was reported to present with a psychiatric disorder.

Additional factors potentially influencing the Dex-CRH test. The Dex-CRH test was administered on average on day 7.9 after admission ( $\mathrm{SD}=3.5$, range $1-14$ days). For 130 patients, the number of usually smoked cigarettes/die and cups of coffee/die as well as number of cigarettes and cups of coffee consumed on the day of the Dex-CRH test up to the test were recorded. In addition, the number of attempts

Table I Demographic Data, Primary Diagnoses, Psychiatric Comorbidities, and Clinical Characteristics of the Sample

\begin{tabular}{lr}
\hline Age in years (mean (SD)) & $48.6(13.94)$ \\
Sex & $\mid 44(61.3 \%)$ \\
Female $(n(\%))$ & $91(38.7 \%)$ \\
Male $(n(\%))$ & \\
& \\
Diagnosis ( $n(\%))$ & $68(28.93 \%)$ \\
Single major depressive episode & $130(55.32 \%)$ \\
Unipolar recurrent episode & $32(13.62 \%)$ \\
Bipolar & $5(2.13 \%)$ \\
Dysthymia & $28(11.91 \%)$ \\
With psychotic features & $235(100 \%)$ \\
Total & \\
Comorbidity ( $n$ (\%)) & $26(11.06 \%)$ \\
Anxiety disorders & $14(5.95 \%)$ \\
Alcohol abuse & $10(4.25 \%)$ \\
Personality disorders (incl. narcissistic, borderline, & \\
avoidant, schizotypal, and not otherwise specified) & $5(2.12 \%)$ \\
Somatoform disorder & \\
Age of onset in years (mean (SD)) & $26.64(7.48)$ \\
Duration of index episode in weeks (mean (SD)) & \\
Number of previous depressive episodes (mean (SD)) & \\
HAM-D (2l-items) at admission (mean (SD)) & $48.21(53.8)$ \\
\hline
\end{tabular}


until successful placement of a venous catheter was documented. For all 235 patients, the weight in the week of the Dex-CRH test, expressed as body mass index $\left(\mathrm{BMI}=\right.$ weight in $\left.\mathrm{kg} /(\text { height in meters })^{2}\right)$, was recorded.

Psychopathology. Severity of psychopathology at admission was assessed using the 21-items Hamilton Depression Rating Scale (HAM-D) by trained raters that included residents in psychiatry and psychologists. In addition to the overall score of the HAM-D, the factorial subscales 'vegetative depression' and 'cognitive depression' according to Overall and Rhoades (1982) were used. Patients also filled out the Beck Depression Inventory (BDI) as a self-rating scale.

History of psychopharmacological treatments. Treatment history was obtained from medical records and from questioning the patients and included the number and type of antidepressant treatment attempts overall and in the present episode and whether the episode exacerbated under an established pharmacotherapy or not. It was also recorded whether patients were treated with mood stabilizers or not, especially lithium and carbamazepine as these drugs have been previously shown to influence the Dex-CRH test (Bschor et al, 2002; von Bardeleben et al, 1988). The presence of benzodiazepine treatment at the time of the Dex-CRH test was also noted.

Satisfactory and unambiguous information could not be obtained for all items in all patients, so that the number of analyzed patients varies slightly among subtests.

\section{The Dex-CRH Test}

The Dex-CRH test was performed as described in detail in Heuser et al (1994b). Briefly, patients were pretreated with $1.5 \mathrm{mg}$ of dexamethasone per os at 2300 . The following day a venous catheter was placed at 1430 and blood was drawn at $1500,1530,1545,1600$, and 1615 into tubes containing EDTA and trasylol (Bayer Inc., Germany). At $1502100 \mu \mathrm{g}$ of human $\mathrm{CRH}$ (Ferring Inc., Kiel, Germany) was administered intravenously. The following parameters were chosen to describe the reaction of the HPA-axis to the Dex-CRH test: (1) the plasma cortisol $\left(\mathrm{CORT}_{1500}\right)$ and $\mathrm{ACTH}\left(\mathrm{ACTH}_{1500}\right)$ concentration at 1500 before administration of $\mathrm{CRH}$ reflecting solely the suppressive effect of dexamethasone; (2) the net area under the curve for the cortisol $\left(C_{\mathrm{AUC}}\right)$ and $\mathrm{ACTH}\left(A_{\mathrm{AUC}}\right)$ concentration curve of the five consecutive blood samples and the maximal cortisol and ACTH concentration ( $C_{\mathrm{MAX}}$ and $A_{\mathrm{MAX}}$ ) reflecting the stimulating effects of $\mathrm{CRH}$ administration.

\section{Hormone Assays}

Hormone assays were identical to those described in detail in Zobel et al (2001). Briefly, for the measurement of plasma cortisol concentrations, a radioimmunoassay (RIA) kit from ICN Biomedicals, Carson, CA was used where the detection limit was $0.3 \mathrm{ng} / \mathrm{ml}$. For plasma ACTH concentrations, an immunometric assay without extraction (Nichols Institute, San Juan Capistrano, CA) was used, with a detection limit of $4.0 \mathrm{pg} / \mathrm{ml}$.

\section{Statistical Analysis}

For the $C_{\mathrm{AUC}}$ and the $A_{\mathrm{AUC}}$, the area under the concentration-time course curve was computed using a trapezoidal integration corrected for baseline (values of cortisol and ACTH concentration at 1500). Statistical analyses were controlled for by age and sex, as previous papers suggested an influence of these factors on the Dex-CRH test (Heuser et al, 1994b; Zobel et al, 2001). Correlation analysis was used to investigate the influence of sex and age in our sample. Partial correlation analyses controlling for sex and age were used to examine the influence of numerical variables on the Dex-CRH test and a nonparametrical correlation analysis for the number of attempts to place a venous catheter, as for only nine subjects more than one attempt was needed. Owing to large sample size differences between compared subgroups for categorical variables, the requirements for parametric tests may have been violated. Therefore, nonparametric tests such as the Kruskall-Wallis $H$-test and Mann-Whitney $U$-test were used. In case of significant association, data were also analyzed with a parametric test, a general linear model with sex and age as covariates in order to assure that effects were not due to group differences in sex and age. To analyze the effects of sex, a general linear model with only age as covariate was taken. The Fisher LSD test was then used as post hoc test. In order to investigate whether highly correlated factors contribute equally or not to the Dex-CRH test, multiple regression analyses (simultaneous inclusion model) with either cortisol- or ACTH-related parameters as the dependent variable were performed. For all parameters, the mean group values are reported. A $p$-value $<0.05$ was taken as the limit for statistical significance. Results with significance levels of $p<0.10$ are reported as trends. In case of multiple group comparisons, significance levels were adjusted according to Bonferroni-Holm (Holm, 1979).

\section{RESULTS}

\section{Effects of Patient Characteristics on the Dex-CRH Test}

Correlation analysis showed a significant effect of sex on $C_{\mathrm{AUC}}(r=0.135, p=0.04)$ and $C_{\mathrm{MAX}}(r=0.176, p=0.007)$, with female patients displaying higher values. There was no effect of sex on $\mathrm{CORT}_{1500}$ or any of the ACTH parameters. Analyses with a general linear model revealed similar results. Female patients had significantly $(p<0.05)$ higher mean $C_{\mathrm{MAX}}$ values $(44.2 \pm$ SEM 3.5 for female and $29.4 \pm 4.4$ for male patients) and $C_{\mathrm{AUC}}$ values $(1857.1 \pm 170.6$ for female and $1272.4 \pm 213.6$ for male patients). Correlation analysis showed no effect of age on any of the investigated parameters, with correlation coefficients not exceeding 0.08. Nonparametric analysis did not show a significant difference in any of the parameters of the Dex-CRH test between bipolar $(n=32)$ vs unipolar $(n=199)$ patients. There was also no significant difference in any of the parameters of the Dex-CRH test in psychotic $(n=28)$ vs nonpsychotic $(n=204)$ patients. Psychotic patients, however, displayed a trend $(p=0.10)$ for higher $\mathrm{CORT}_{1500}$ values $(31.1 \mathrm{ng} / \mathrm{ml}(\mathrm{SEM}=4.9)$ for psychotic patients and $22.9 \mathrm{ng} / \mathrm{ml}$ (1.8) for nonpsychotic patients). Nonparametric analysis did not detect any effect 
of the presence of comorbid psychiatric disorders overall ( $n=50$ of 235 ) or for the presence of comorbid alcohol abuse $(n=14)$, anxiety $(n=26)$, personality $(n=10)$, or somatoform disorder $(n=5)$ analyzed individually. Lower CORT $_{1500}$ values could be observed in patients with a positive family history $(n=124)$ than in patients with a negative family history $(n=103)$ (analysis with general linear model: $\mathrm{F}_{1,218}=4.6 ; p=0.03$; analysis with MannWhitney test: $p=0.08$ ), but no significant differences in any of the other parameters. A partial correlation analysis showed a significant positive correlation of the number of previous episodes with $C_{\mathrm{AUC}}(r=0.18 ; p<0.01), C_{\mathrm{MAX}}$ $(r=0.16 ; p=0.022)$ and $A_{\mathrm{MAX}}(r=0.14 ; p=0.041)$ and $\mathrm{a}$ trend for $\mathrm{A}_{\mathrm{AUC}}(r=0.12 ; p=0.075)$, but no correlation of any of the investigated parameters with age of onset or duration of the index episode (see Table 2).

\section{Effects of Additional Factors on the Dex-CRH Test}

In a partial correlation analysis controlling for sex and age, there was no significant association of the BMI with any of the parameters except for a trend for a negative correlation with $\mathrm{ACTH}_{1500} \quad(r=-0.13 ; p=0.078)$. There was no significant correlation with the amount of consumed cups of coffee overall and on the day of the Dex-CRH test and with the number of attempts needed to successfully place a venous catheter. There was a significant positive correlation for the number of cigarettes smoked per day and $A_{\mathrm{AUC}}$ $(r=0.27 ; p=0.015)$ and $A_{\mathrm{MAX}}(r=0.29 ; p<0.01)$ but not for $\mathrm{ACTH}_{1500}$ or any of the cortisol-related values. The difference of usually smoked cigarettes to those smoked on the day of the Dex-CRH test showed no significant correlation with any of the parameters (see Table 3).

\section{Effects of Psychopathology on the Dex-CRH Test}

In a partial correlation analysis, a significant positive correlation between the overall HAM-D score and CORT $\mathrm{C}_{1500}$ $(r=0.17 ; p<0.02)$ and a trend for a correlation with $\mathrm{ACTH}_{1500}(r=0.11 ; p=0.09)$ was found. This was also true for the HAM-D subscale for 'vegetative depression' $\left(\mathrm{CORT}_{1500}: r=0.16, p<0.05 ; \mathrm{ACTH}_{1500}: r=0.13, p=0.06\right)$ but not for 'cognitive depression'. Overall scores of the BDI did not show a significant correlation with any of the investigated parameters (see Table 4).

\section{Current Psychopharmacological Treatment}

We first investigated whether the type of current antidepressant treatment affected the outcome of the Dex-CRH test. In all, 32 patients did not receive any medication at the time of the Dex-CRH test. The other patients were divided according to the class of the administered antidepressants, the largest groups being selective serotonin reuptake inhibitors (SSRIs) $(N=58)$, tricyclic antidepressants $(N=37)$, and mirtazapine $(N=27)$. A general linear model

Table 2 Associations between Disease History and Dex-CRH Test Results

\begin{tabular}{|c|c|c|c|c|c|c|}
\hline & CORT $_{1500}$ & $C_{A U C}$ & $C_{\text {MAX }}$ & $\mathrm{ACTH}_{1500}$ & $A_{\text {AUC }}$ & $A_{\text {MAX }}$ \\
\hline Age of onset & $p=0.198$ & $\begin{array}{r}-0.056 \\
p=0.400\end{array}$ & $\begin{array}{r}-0.046 \\
p=0.484\end{array}$ & $p=0.143$ & $\begin{array}{r}-0.080 \\
p=0.232\end{array}$ & $\begin{array}{r}-0.080 \\
p=0.232\end{array}$ \\
\hline Duration of episode & -0.087 & 0.014 & 0.020 & -0.016 & $\begin{array}{r}0.015 \\
0.04\end{array}$ & 0.002 \\
\hline No. of previous episodes & $\begin{array}{r}-0.056 \\
p=0.424\end{array}$ & $p=0.009$ & $p=0.022$ & $\begin{array}{r}-0.056 \\
p=0.427\end{array}$ & $p=0.041$ & $p=0.075$ \\
\hline
\end{tabular}

Age of onset $N=235$, number of previous episodes $N=208$, duration of index episode $N=227$.

Table 3 Associations between Weight, Cigarette and Caffeine Consumption, Attempts to Place the Venous Catheter and Dex-CRH Test Results

\begin{tabular}{|c|c|c|c|c|c|c|}
\hline & CORT $_{1500}$ & $C_{\text {AUC }}$ & $C_{\text {MAX }}$ & $\mathbf{A C T H}_{1500}$ & $A_{\text {Auc }}$ & $A_{\text {MAX }}$ \\
\hline \multirow[t]{2}{*}{ BMI } & -0.084 & -0.032 & -0.025 & -0.130 & -0.072 & -0.069 \\
\hline & $p=0.233$ & $p=0.649$ & $p=0.717$ & $p=0.078$ & $p=0.314$ & $p=0.328$ \\
\hline \multirow[t]{2}{*}{ Cigarettes/day } & 0.053 & 0.087 & 0.123 & 0.081 & 0.270 & 0.290 \\
\hline & $p=0.547$ & $p=0.330$ & $p=0.164$ & $p=0.366$ & $p=0.015$ & $p=0.006$ \\
\hline \multirow[t]{2}{*}{$\Delta$ cigarettes at the test day } & -0.073 & 0.097 & 0.120 & -0.024 & 0.128 & 0.113 \\
\hline & $p=0.509$ & $p=0.385$ & $p=0.277$ & $p=0.833$ & $p=0.266$ & $p=0.321$ \\
\hline \multirow[t]{2}{*}{ Cups of coffee/day } & 0.106 & -0.011 & 0.012 & 0.101 & 0.066 & 0.055 \\
\hline & $p=0.226$ & $p=0.898$ & $p=0.884$ & $p=0.257$ & $p=0.460$ & $p=0.534$ \\
\hline \multirow[t]{2}{*}{$\Delta$ coffee at the test day } & 0.076 & -0.035 & -0.030 & 0.048 & 0.028 & 0.015 \\
\hline & $p=0.392$ & $p=0.695$ & $p=0.736$ & $p=0.589$ & $p=0.752$ & $p=0.868$ \\
\hline \multirow[t]{2}{*}{ No. of attempts to place the venous catheter } & 0.008 & -0.048 & -0.056 & 0.127 & -0.047 & -0.026 \\
\hline & $p=0.376$ & $p=0.589$ & $p=0.521$ & $p=0.153$ & $p=0.600$ & $p=0.771$ \\
\hline
\end{tabular}

$\mathrm{N}=235$ for $\mathrm{BMI}$ and 130 for all other parameters.

$\Delta$ indicates difference between consumption at the test day compared to usual consumption. 
Table 4 Associations between PSYchopathology and Dex-CRH Test Results

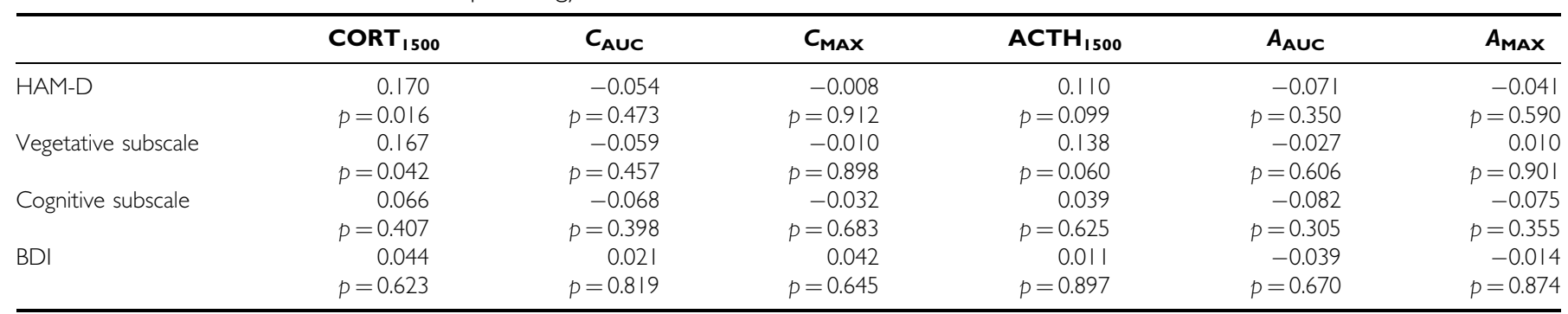

$N=235$ for all HAM-D-related variables and $N=158$ for $\mathrm{BDI}$.

showed no significant effect of type of antidepressant treatment on any of the Dex-CRH test parameters.

We then separately focused on the effects of lithium and carbamazepine on the test, cortisol and ACTH responses of patients receiving lithium at the time of the Dex-CRH test $(n=21)$, carbamazepine $(n=9)$, or neither of those $(n=167)$ were compared (see Figure 1). A Kruskal-Wallis test showed overall treatment effects for $C_{\mathrm{AUC}}(p=0.007)$, $C_{\mathrm{MAX}}(p=0.022)$, and $A_{\mathrm{AUC}} \quad(p=0.018)$ and $A_{\mathrm{MAX}}$ $(p=0.038)$. Post hoc analysis (Mann-Whitney test) showed no significant differences for all variables between patients receiving neither lithium nor carbamazepine and patients treated with lithium and between patient treated with lithium or carbamazepine. All the above-cited parameters, however, were significantly higher in patients treated with carbamazepine $v s$ patients not receiving mood stabilizers. Similar overall results were found in the parametric analysis. A significant overall effect of the different treatment modalities was observed for $C_{\mathrm{AUC}}\left(\mathrm{F}_{2,197}=8.3\right.$; $p<0.001), A_{\mathrm{AUC}}\left(\mathrm{F}_{2,197}=12.3 ; p<0.001\right), C_{\mathrm{MAX}}\left(\mathrm{F}_{2,197}=5.8\right.$; $p<0.005)$, and $A_{\operatorname{MAX}}\left(\mathrm{F}_{2,197}=12.1 ; p<0.001\right)$, but not for $\mathrm{CORT}_{1500}$ or $\mathrm{ACTH}_{1500}$. There were no significant differences in any of the parameters between patients receiving any benzodiazepines at the time of the Dex-CRH test $(n=118)$ or not $(n=108)$.

\section{History of Psychopharmacological Treatment}

A partial correlation analysis showed no correlation of any of the investigated Dex-CRH test parameters with the number of antidepressant treatment trial in the index episode or overall. Nonparametric analysis showed significant differences between patients whose episode started under an established psychopharmacotherapy $(n=36) v s$ patients who were not treated $(n=160)$ at the time of the onset of the current episode (see Figure 2). Patients in the first group had significantly higher values of $C_{\mathrm{AUC}}$ $(p<0.005), C_{\mathrm{MAX}}(p=0.005)$ and a trend for higher $A_{\mathrm{AUC}}$ $(p=0.061)$ and $A_{\mathrm{MAX}}(p=0.071)$. Analysis with a general linear model also showed significantly higher values in the first group for the group mean values of $C_{\mathrm{AUC}}\left(\mathrm{F}_{1,195}=14.2\right.$; $p<0.001), A_{\mathrm{AUC}}\left(\mathrm{F}_{1,196}=8.7 ; p<0.003\right), C_{\mathrm{MAX}}\left(\mathrm{F}_{1,196}=13.5\right.$; $p<0.001)$, and $A_{\mathrm{MAX}}\left(\mathrm{F}_{1,196}=9.5 ; p<0.005\right)$, but not for $\mathrm{CORT}_{1500}$ or $\mathrm{ACTH}_{1500}$.

To investigate whether the effects of relapsing under an existing psychopharmacotherapy were only due to the effects of lithium or carbamazepine, only patients not receiving either lithium or carbamazepine were compared for the effect of relapsing under pharmacotherapy $(n=17)$
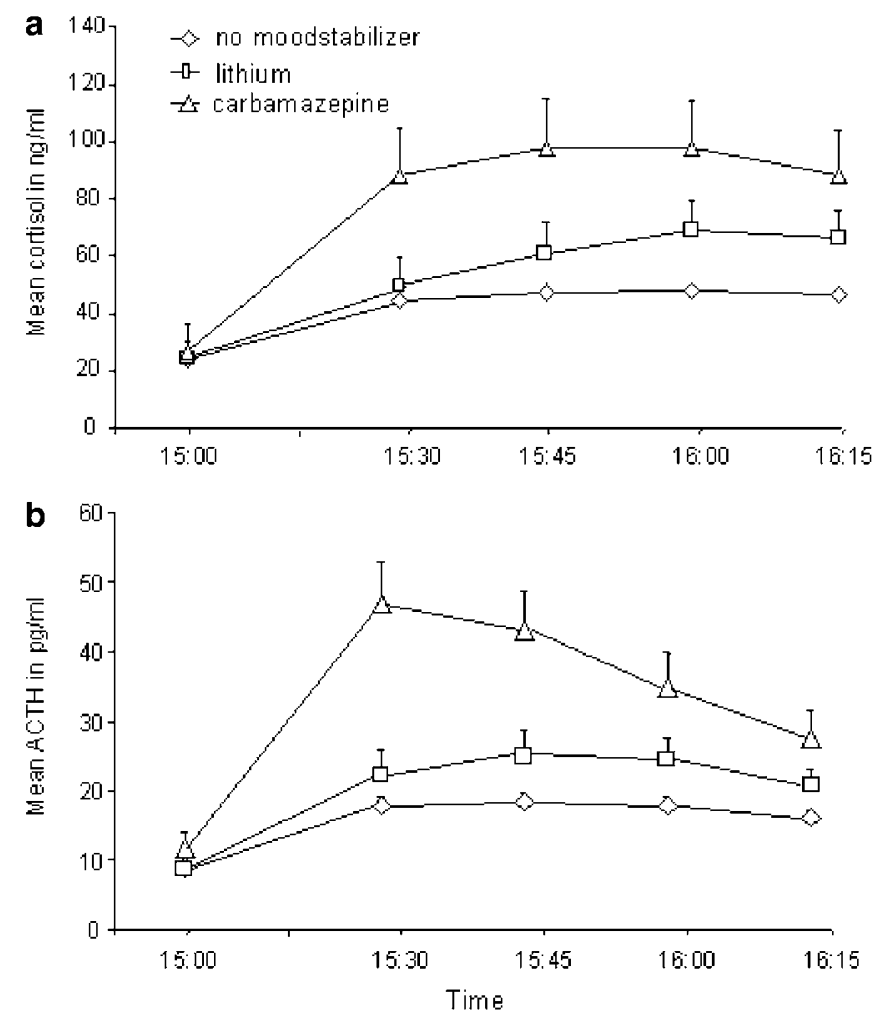

Figure I Effects of carbamazepine $(N=9)$ and lithium treatment $(N=2 I)$ at the time of the Dex-CRH test on the cortisol (a) and ACTH (b) response in this test. $p<0.05$ for difference between patients receiving carbamazepine and patients in the two other groups. $N=167$ for the no mood stabilizer group.

$v s$ relapsing without pre-established pharmacotherapy $(n=127)$. Here a parametric analysis still showed significantly higher values for patients who relapsed under pharmacotherapy for $C_{\mathrm{AUC}}(p<0.001), C_{\mathrm{MAX}}(p<0.001)$, $A_{\mathrm{MAX}}(p=0.04)$ and a trend for $\mathrm{A}_{\mathrm{AUC}}(p=0.08)$ but not for any of the other values.

\section{Multiple Regression Analysis}

Relapse under pharmacotherapy, intake of mood stabilizers, and the number of previous episodes are likely confounding factors of each other. To assess the individual contribution of these three factors, we used a linear regression analysis (also including sex and age as variables) with $C_{\mathrm{AUC}}, C_{\mathrm{MAX}}$, $A_{\mathrm{AUC}}$, and $A_{\mathrm{MAX}}$ as the dependent variables. For $C_{\mathrm{AUC}}$, there was an overall significant influence of these variables 


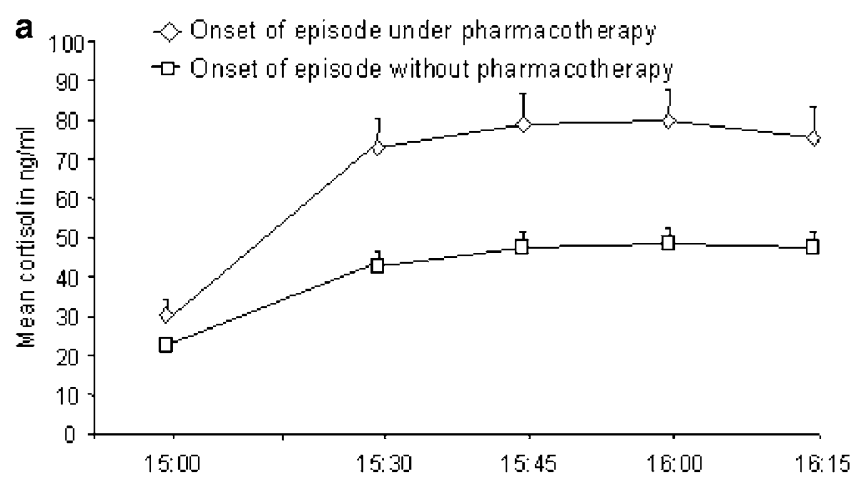

hyperfunction. Interestingly, only the severity of vegetative symptoms, including sleep and appetite abnormalities and other somatic symptoms, but not the symptom complex directly related to depressive mood correlated with the Dex$\mathrm{CRH}$ test.

\section{Factors Related to Patient Characteristics}

The influence of sex and age on the HPA-axis has been documented in several studies. In our sample, we observed a strong influence of sex on the cortisol but not on the ACTH response in the Dex-CRH test, with female patients displaying higher values. These data are in accordance with the results from Heuser et al (1996), where healthy women show higher cortisol and ACTH plasma concentrations than healthy men, and with the data from Zobel et al (2001), who report a trend for a higher cortisol response in the Dex-CRH test in depressed females than in males. In addition, the reciprocal influence of female sex hormones and the HPAaxis has been well established in clinical and preclinical studies. In rodents, female animals have a more pronounced activation of the HPA-axis following stress than male animals. Overall, data indicate that while estrogens can enhance HPA-axis activity (also by directly stimulating $\mathrm{CRH}$ expression), androgens appear to have the opposite effect (see Handa et al (1994) and Magiakou et al (1997) for review). Recently, estrogen beta-receptors have been found to be colocalized with vasopressin in the paraventricular nucleus, indicating that direct effects of estrogen on hypothalamic stress peptides are possible (Isgor et al, 2003). In fact, the HPA-axis enhancing effects of estrogens but not androgens might be one factor contributing to the higher prevalence of mild to moderate depressive disorders in women (Wittchen et al, 1994). In contrast to other reports, we did not observe any influence of age on the magnitude of the HPA-axis response in depressed patients. Previous studies using smaller sample sizes have reported an influence of age on the CRH stimulation test in depressed patients (von Bardeleben and Holsboer, 1991) and a better discrimination of the Dex-CRH test and dexamethasone suppression test between patients and controls if subjects were matched by age (Bryer et al, 1985; Heuser et al, 1994a). Davis et al (1984) also found a higher percentage of depressed patients with hyperactive HPA-axis, as measured by the dexamethasone suppression test, among older individuals. Several animal studies have also reported an effect of age on the responsiveness of the HPA-axis, with the hypothalamic peptide vasopressin (synergizing ACTH release with $\mathrm{CRH}$ ) being an important element in agerelated changes (for review see Hatzinger et al, 2000; Keck et al, 2000; Swaab, 1995). At least for acutely depressed patients, our study cannot confirm these findings. In our sample, disease-related factors may override the effects of age.

Opposing previous studies on HPA-axis abnormalities in bipolar depressed patients, we did not find a significant difference in cortisol and ACTH responses in the Dex-CRH test of bipolar $v s$ unipolar. In a small study performed by Rybakowski and Twardowska (1999), a significantly higher cortisol response in the Dex-CRH test was found in patients with bipolar disorder as compared to patients with unipolar disorder. Even though in our sample the mean responses in 
the Dex-CRH test in bipolar patients were elevated compared to unipolar depressed patients, this difference did not reach statistical significance. In the study by Rybakowski and Twardowska (1999), unipolar depressed patients only showed a marginal HPA-axis abnormality, which is an observation that we also made for a proportion of our patients. The dramatically different Dex-CRH test response in bipolar $v s$ unipolar patients may be a result specific to outliers in this rather small sample of patients (16 bipolar and 24 unipolar patients). A series of studies have observed an increased HPA-axis activity in psychotic patients. A consistent finding in these studies is the fact that psychotic depressed patients are significantly more often nonsuppressors in the DST and a more recent paper described an increased $24 \mathrm{~h}$ ACTH secretion in psychotic depressed $v s$ nonpsychotic depressed patients and healthy controls (Nelson and Davis, 1997; Posener et al, 2000). In accordance with these findings, we found a trend for higher CORT $_{1500}$ values in psychotic patients. CORT $_{1500}$ values represent the post-dexamethasone cortisol values before CRH stimulation and are thus comparable to the DST. We did however not find any differences between psychotic and nonpsychotic in the cortisol or ACTH response following $\mathrm{CRH}$ stimulation. This suggests that HPA-axis abnormalities in psychotic patients may be limited to HPA-axis functions specifically tested in the DST but not the CRH stimulation, likely more closely related to glucocorticoid receptor resistance and not hypothalamic $\mathrm{CRH}$ or vasopressin hyperdrive.

There was no correlation of age of onset and duration of the index episode with the cortisol and ACTH responses in the Dex-CRH test. We could, however, observe a positive correlation of the ACTH and cortisol response with the number of previous episodes. Similar results were shown by Hatzinger et al (2002), who also found a positive correlation of the number of previous episodes with the cortisol response in the Dex-CRH test but not the overall duration of illness. Repetitive states of HPA-axis hyperactivity may by themselves alter the responsiveness of the stress-hormone system, by for example changing the DNA-methylation status in the promoter regions of glucocorticoid-responsive genes (Kagoshima et al, 2001; Thomassin et al, 2001). The number of previous depressive episodes is, however, confounded by two factors that are also associated by an increase in Dex-CRH test response, the intake of carbamazepine and the fact of relapsing under an established pharmacotherapy. Further below we will discuss the results of a regression analysis, trying to evaluate which of these three factors individually contribute to the increased HPAaxis activity.

\section{Additional Factors Influencing the Dex-CRH Test}

Several studies have described that nicotine stimulates central stress-related structures and increases ACTH and cortisol release in laboratory animals (Matta et al, 1998; Rhodes et al, 2001). Indeed, we also observed an influence of the number of smoked cigarettes per day on the ACTH but not on the cortisol response in the Dex-CRH test. An HPA-axis stimulating effect has also been described for nicotine withdrawal (Frederick et al, 1998; Pickworth et al, 1996). Nevertheless, we did not observe a correlation between the difference of usually smoked cigarettes/day and those smoked on the day of the Dex-CRH test and the $\mathrm{ACTH}$ and cortisol response in the Dex-CRH test.

Caffeine intake is able to activate directly the HPA-axis (Nicholson, 1989; Nicholson et al, 1987; Holsboer-Trachsler et al, 1987) and could thus potentially influence the response in the Dex-CRH test. In this sample of acutely depressed patients, we did not observe an effect of caffeine. We also did not observe a significant influence of the BMI on the responsiveness of the HPA-axis. Several studies suggest a close relationship between factors secreted by the adipose tissue, such as leptin, and the HPA-axis (Casanueva and Dieguez, 1999). Obese subjects have been reported to have a markedly higher cortisol and ACTH response in the $\mathrm{CRH}$ stimulation test than lean subjects (Faloia et al, 2000). No effect of the number of attempts needed to place a venous catheter, which would represent a mild to moderate acute stressor to patients, was noted. Numerous animal and human studies have shown the HPA-axis activating effects of acute stress (Habib et al, 2001; Miller and O'Callaghan, 2002). Our findings are, however, in accordance with a study by Oshima et al (2001), where no effect of acute stressors including cold stress and psychological stressors was observed on the Dex-CRH test in healthy volunteers.

Overall, the fact that we did not observe a consistent influence of factors that are known to stimulate or modulate HPA-axis activity on the Dex-CRH in depressed patient may indicate a ceiling effect of HPA-axis stimulation by the depressive disorder itself. Other modulators may not be able to alter or enhance this pre-existent state of hyperreactivity in depression.

\section{Psychopathology}

A series of previous studies have documented an influence of the severity of the psychopathology on the magnitude of the HPA-axis response in the Dex-CRH test. Zobel et al (2001) reported a direct positive correlation of the HAM-D scores with the cortisol response in the Dex-CRH test. In our sample, we also found a significant positive correlation of the HAM-D score at admission and CORT $_{1500}$ but not $\mathrm{C}_{\mathrm{AUC}}$ or $C_{\mathrm{MAX}}$. In contrast to Zobel et al (2001), our calculation for the area under the curve of the cortisol response is corrected by the baseline cortisol value $\mathrm{CORT}_{1500}$. If the cortisol AUC values not corrected for baseline are used (as used in Zobel et al, 2001), we also find a positive correlation of the HAM-D scores with the overall cortisol response. Our data are also in agreement with data reported for the dexamethasone suppression test, which is comparable to the CORT ${ }_{1500}$ value (Holsboer et al, 1987).

When analyzing the factorial HAM-D subscales 'cognitive depression' vs 'vegetative depression' according to Overall and Rhoades (1982), significant correlations were only found with the subscale reflecting the severity of vegetative symptoms including somatic anxiety and somatic symptoms such as hypochondriasis, sleep disturbances, decreased appetite, decreased libido, and diurnal variation. This is in accordance with the hypothesis of an enhanced $\mathrm{CRH}$ neurotransmission in depression influencing both the HPA-axis and limbic systems. Work in laboratory animals indicates that increased $\mathrm{CRH}$ neurotransmission may be responsible for a series of the symptoms seen in depression. 
Intracerebroventricular administration of CRH in monkeys and rodents leads to anxiety, anorexia, and sleep disturbances in these animals (Holsboer, 2000 for review). This may also suggest that increased CRH activity in depressed patients only mediates a part of the spectrum of clinical symptoms seen in depression and that patients with prominent somatic complaints may belong to a biologically distinct subtype of this disorder.

\section{Effects of Psychopharmacological Treatment}

We could not show an association of presence or absence of antidepressant treatment, the type of antidepressant treatment or of the number of previous ineffective antidepressant treatment attempts before hospitalization and the results of the Dex-CRH test, indicating that the reported normalizing effect of antidepressant treatment on the Dex$\mathrm{CRH}$ test is actually dependent on clinical improvement and not just a pharmacological side effect (Holsboer et al, 1987; Holsboer-Trachsler et al, 1991; Nickel et al, 2003). On the other hand, the fact of relapsing under an established prophylactic psychopharmacotherapy enhances the ACTH as well as cortisol response. As mood stabilizers are often used as prophylactic treatment, this effect may be attributable to Dex-CRH test response-enhancing effects of carbamazepine and lithium. Similar to our findings, von Bardeleben et al (1988) reported that carbamazepine increases ACTH and cortisol concentration at baseline and after CRH stimulation and Zobel et al (2001) a carbamazepine-induced increase in ACTH and cortisol in the Dex$\mathrm{CRH}$ test. These observations may be explained by the fact that this drug induces CYP3A3/4 (a member of the cytochrome $P 450$ family) activity leading to an increased metabolism and clearance of dexamethasone via CYP3A3/4 and thus to lower dexamethasone plasma concentrations and insufficient suppression of the HPA-axis in the test (Guthrie, 1991; Wang and Ketter, 2002). Lithium has also been shown to independently increase HPA-axis activity (Bschor et al, 2002). In our sample, patients treated with lithium showed nonsignificantly higher responses in the Dex-CRH test than patients not receiving any mood stabilizers, so that we cannot fully confirm the effects observed by Bschor et al (2002) in this sample. It has to be pointed out, however, that we investigated only 21 patients treated with lithium at the time of the Dex-CRH test. The effect of relapsing under psychopharmacotherapy, however, remained significant when only patients not receiving any mood stabilizers but antidepressant drugs alone were analyzed. One possible explanation of this effect may be that patients relapsing without an established pharmacotherapy are also more likely to have no medication at the time of the test. Indeed 26 patients in this group $v s$ only two in the treated group were medicated at the time of the test. The cortisol and ACTH response in the group of patients not medicated at the time of the Dex-CRH test however did not differ from medicated patients. In our view, the intake of antidepressants at the onset of an episode does appear to have an independent effect on HPA-axis reactivity, even though it may be months from the actual test. The enhanced HPA-axis reactivity in patients relapsing under antidepressant treatment may be the consequence of the effects of antidepressant-induced changes in gene expression in a variety of tissues. Altered hepatic metabolism of glucocorticoids including dexamethasone due to changes in cytochrome $P 450$ enzyme activity may change the baseline activity of the HPA-axis. It has also been shown that the transport of glucocorticoids through the blood-brain barrier via transporter molecules such as p-glycoprotein is essential for the regulation of the HPA-axis (Uhr et al, 2000; Uhr and Grauer, 2003). Antidepressant drugs are not only substrates for p-glycoprotein but in vitro experiments have shown that they can by themselves alter p-glycoprotein function (Pariante et al, 2003). Furthermore, antidepressants have been shown to increase gene expression in selected brain regions, including the expression of glucocorticoid and mineralocorticoid receptors (for review see Holsboer and Barden, 1996). Brain-specific changes in gene expression as well as an altered activity of cytochrome P450 enzymes or of p-glycoprotein could result in a basal imbalance of the HPA-axis. In case of relapse, this may then contribute to the excessively enhanced activity of this system.

\section{Regression Analysis}

As stated above, we found that the number of previous episodes, the intake of carbamazepine and lithium, and the relapse under an established pharmacotherapy were all positively correlated with the response in the Dex-CRH test. These three variables, however, strongly interact with each other, making an interpretation of the data difficult. To identify which of these factors contribute independently to the cortisol or ACTH response, we performed a regression analysis, including these three variables as well as sex and age. Regression analysis revealed that only relapse under pharmacotherapy and female sex appeared to contribute significantly to the response in the Dex-CRH test. A regression analysis gives the independent effect of a variable on a criterion controlling for the effects of the other variables. When the variables are highly correlated, which is the case in our sample, a nonsignificant contribution of a variable does not exclude any relevant effects at all, but indicates that the effects are better represented by those variables with a significant contribution. It is thus possible that repetitive states of HPA-axis hyperactivity during previous depressive episodes as well as an altered HPAaxis set point due to continuous antidepressant intake, both enhance HPA-axis reactivity. It is also conceivable that patients with a recurrent depressive disorders, who are more likely to relapse under pharmacotherapy, represent a biologically distinct subgroup of patients, featuring enhanced cortisol and ACTH responses in the Dex-CRH test.

\section{Conclusions}

Overall, our data indicate that in acutely depressed inpatients, the Dex-CRH test is only influenced by few variables. The most important variables to control for in interpreting this test seem to be gender and the intake of carbamazepine, while other factors such as age, the presence or absence of antidepressant medication, or the type of antidepressant medication do not appear to have a strong influence. Cigarette consumption only has to be accounted for when analyzing the ACTH response. The fact 
that acute stress does not appear to impact test results, suggests that the wall-through technique may not be required. Keeping consistent conditions for all investigated patients regardless of the used technique is nevertheless immensely important. We believe that the results of this study could facilitate the design and interpretation of future Dex-CRH test studies and may therefore enhance its clinical usefulness. It has to be mentioned that all data have been collected in in-patients, so that these findings may not be directly extended to an outpatient setting.

The range of responses in the Dex-CRH test in depressed patients is thus influenced by several factors, including treatment modalities. There is, however, an independent effect of disease-related elements that explains part of this variance. A higher number of recurrent episodes and more prominent somatic symptoms are correlated with a more dysregulated HPA-axis. One possible interpretation of these data is that there might be biologically distinct subtypes of patients with depression who could be distinguished according to their HPA-axis status during a depressive episode, especially if treatment modalities are taken into account. In fact, an insertion/deletion polymorphism in the angiotensin converting enzyme gene has been associated with a genotype-dependent difference in the magnitude of the Dex-CRH test (Baghai et al, 2002). One might therefore envisage to use this test as an endophenotype to distinguish pathogenetically different and genetically more homogeneous groups of depressed patients for genetic case/control association studies (Almasy and Blangero, 2001).

\section{REFERENCES}

Almasy L, Blangero J (2001). Endophenotypes as quantitative risk factors for psychiatric disease: rationale and study design. $A m \mathrm{~J}$ Med Genet 105: 42-44.

Baghai TC, Schule C, Zwanzger P, Minov C, Zill P, Ella R et al (2002). Hypothalamic-pituitary-adrenocortical axis dysregulation in patients with major depression is influenced by the insertion/deletion polymorphism in the angiotensin I-converting enzyme gene. Neurosci Lett 328: 299-303.

Bryer JB, Borrelli DJ, Matthews Jr EJ, Kornetsky C (1985). The dexamethasone suppression test in depression: some correlates. Biol Psychiatry 20: 814-815.

Bschor T, Adli M, Baethge C, Eichmann U, Ising M, Uhr M et al (2002). Lithium augmentation increases the ACTH and cortisol response in the combined DEX/CRH test in unipolar major depression. Neuropsychopharmacology 27: 470-478.

Casanueva FF, Dieguez C (1999). Neuroendocrine regulation and actions of leptin. Front Neuroendocrinol 20: 317-363.

Davis KL, Davis BM, Mathe AA et al (1984). Age and the dexamethasone suppression test in depression. Am J Psychiatry 141: 872-874.

Faloia E, Camilloni MA, Giacchetti G, Mantero F (2000). Adipose tissue as an endocrine organ? A review of some recent data. Eat Weight Disord 5: 116-123.

Frederick SL, Reus VI, Ginsberg D, Hall SM, Munoz RF, Ellman G (1998). Cortisol and response to dexamethasone as predictors of withdrawal distress and abstinence success in smokers. Biol Psychiatry 43: 525-530.

Gold PW, Loriaux DL, Roy A, Kling MA, Calabrese JR, Kellner CH et al (1986). Responses to corticotropin-releasing hormone in the hypercortisolism of depression and Cushing's disease. Pathophysiologic and diagnostic implications. $N$ Engl J Med 314: 1329-1335.
Guthrie S (1991). The impact of dexamethasone pharmacokinetics on the DST: a review. Psychopharmacol Bull 27: 565-576.

Habib KE, Gold PW, Chrousos GP (2001). Neuroendocrinology of stress. Endocrinol Metab Clin N Am 30: 695-728; vii-viii.

Halbreich U, Asnis GM, Shindledecker R, Zumoff B, Nathan RS (1985). Cortisol secretion in endogenous depression. I. Basal plasma levels. Arch Gen Psychiatry 42: 904-908.

Handa RJ, Burgess LH, Kerr JE, O’Keefe JA (1994). Gonadal steroid hormone receptors and sex differences in the hypothalamopituitary-adrenal axis. Horm Behav 28: 464-476.

Hatzinger M, Hemmeter UM, Baumann K, Brand S, HolsboerTrachsler E (2002). The combined DEX-CRH test in treatment course and long-term outcome of major depression. J Psychiatr Res 36: 287-297.

Hatzinger M, Wotjak CT, Naruo T et al (2000). Endogenous vasopressin contributes to hypothalamic-pituitary-adrenocortical alterations in aged rats. J Endocrinol 164: 197-205.

Heuser IJ, Gotthardt U, Schweiger U et al (1994a). Age-associated changes of pituitary-adrenocortical hormone regulation in humans: importance of gender. Neurobiol Aging 15: 227-231.

Heuser I, Yassouridis A, Holsboer F (1994b). The combined dexamethasone/CRH test: a refined laboratory test for psychiatric disorders. J Psychiatr Res 28: 341-356.

Heuser IJ, Schweiger U, Gotthardt U et al (1996). Pituitaryadrenal-system regulation and psychopathology during amitriptyline treatment in elderly depressed patients and normal comparison subjects. Am J Psychiatry 153: 93-99.

Holm S (1979). A simple sequentially rejective multiple test procedure. Scand J Stat 6: 65-70.

Holsboer F (1999). The rationale for corticotropin-releasing hormone receptor (CRH-R) antagonists to treat depression and anxiety. J Psychiatr Res 33: 181-214.

Holsboer F (2000). The corticosteroid receptor hypothesis of depression. Neuropsychopharmacology 23: 477-501.

Holsboer F, von Bardeleben U, Gerken A, Stalla GK, Muller OA (1984). Blunted corticotropin and normal cortisol response to human corticotropin-releasing factor in depression. $N$ Engl J Med 311: 1127.

Holsboer F, von Bardeleben U, Wiedemann K, Muller OA, Stalla GK (1987). Serial assessment of corticotropin-releasing hormone response after dexamethasone in depression. Implications for pathophysiology of DST nonsuppression. Biol Psychiatry 22: 228-234.

Holsboer F, Barden N (1996). Antidepressants and hypothalamicpituitary-adrenocortical regulation. Endocr Rev 17: 187-205.

Holsboer F, Lauer CJ, Schreiber W, Krieg JC (1995). Altered hypothalamic-pituitary-adrenocortical regulation in healthy subjects at high familial risk for affective disorders. Neuroendocrinology 62: 340-347.

Holsboer-Trachsler E, Buol C, Wiedemann K, Holsboer F (1987). Dexamethasone suppression test in severe schizophrenic illness: effects of plasma dexamethasone and caffeine levels. Acta Psychiatr Scand 75: 608-613.

Holsboer-Trachsler E, Stohler R, Hatzinger M (1991). Repeated administration of the combined dexamethasone-human corticotropin releasing hormone stimulation test during treatment of depression. Psychiatry Res 38: 163-171.

Isgor C, Shieh KR, Akil H, Watson SJ (2003). Colocalization of estrogen beta-receptor messenger RNA with orphanin FQ, vasopressin and oxytocin in the rat hypothalamic paraventricular and supraoptic nuclei. Anat Embryol 11: 11.

Kagoshima M, Wilcke T, Ito $\mathrm{K}$ et al (2001). Glucocorticoidmediated transrepression is regulated by histone acetylation and DNA methylation. Eur J Pharmacol 429: 327-334.

Kalin NH, Shelton SE, Kraemer GW, McKinney WT (1983). Corticotropin-releasing factor administered intraventricularly to rhesus monkeys. Peptides 4: 217-220. 
Keck ME, Hatzinger M, Wotjak CT, Landgraf R, Holsboer F, Neumann ID (2000). Ageing alters intrahypothalamic release patterns of vasopressin and oxytocin in rats. Eur J Neurosci 12: 1487-1494.

Magiakou MA, Mastorakos G, Webster E, Chrousos GP (1997). The hypothalamic-pituitary-adrenal axis and the female reproductive system. Ann N Y Acad Sci 816: 42-56.

Matta SG, Fu Y, Valentine JD, Sharp BM (1998). Response of the hypothalamo-pituitary-adrenal axis to nicotine. Psychoneuroendocrinology 23: 103-113.

Miller DB, O'Callaghan JP (2002). Neuroendocrine aspects of the response to stress. Metabolism 51: 5-10.

Mitchell AJ (1998). The role of corticotropin releasing factor in depressive illness: a critical review. Neurosci Biobehav Rev 22: 635-651.

Modell S, Yassouridis A, Huber J, Holsboer F (1997). Corticosteroid receptor function is decreased in depressed patients. Neuroendocrinology 65: 216-222.

Nelson JC, Davis JM (1997). DST studies in psychotic depression: a meta-analysis. Am J Psychiatry 154: 1497-1503.

Nemeroff CB, Owens MJ, Bissette G, Andorn AC, Stanley M (1988). Reduced corticotropin releasing factor binding sites in the frontal cortex of suicide victims. Arch Gen Psychiatry 45: 577-579.

Nemeroff CB, Widerlov E, Bissette G et al (1984). Elevated concentrations of CSF corticotropin-releasing factor-like immunoreactivity in depressed patients. Science 226: 1342-1344.

Nicholson SA (1989). Stimulatory effect of caffeine on the hypothalamo-pituitary-adrenocortical axis in the rat. $J$ Endocrinol 122: 535-543.

Nicholson SA, Campbell EA, Gillham B, Jones MT (1987). Recovery of the components of the hypothalamo-pituitary-adrenocortical axis in the rat after chronic treatment with prednisolone. $J$ Endocrinol 113: 239-247.

Nickel T, Sonntag A, Schill J, Zobel AW, Ackl N, Brunnauer A et al (2003). Clinical and neurobiological effects of tianeptine and paroxetine in major depression. J Clin Psychopharmacol 23: 155-168.

Oshima A, Miyano H, Yamashita S et al (2001). Psychological, autonomic and neuroendocrine responses to acute stressors in the combined dexamethasone/CRH test: a study in healthy subjects. J Psychiatr Res 35: 95-104.

Overall JE, Rhoades HM (1982). Use of the Hamilton Rating Scale for classification of depressive disorders. Compr Psychiatry 23: 370-376.

Owens MJ, Nemeroff CB (1991). Physiology and pharmacology of corticotropin-releasing factor. Pharmacol Rev 43: 425-473.

Pariante CM, Hye A, Williamson R, Makoff A, Lovestone S, Kerwin RW (2003). The antidepressant clomipramine regulates cortisol intracellular concentrations and glucocorticiod receptor expression in fibroblasts and rat primary neurones. Neuropsychopharmacology 10: 1553-1561.
Pickworth WB, Baumann MH, Fant RV, Rothman RB, Henningfield JE (1996). Endocrine responses during acute nicotine withdrawal. Pharmacol Biochem Behav 55: 433-437.

Posener JA, DeBattista C, Williams GH, Chmura Kraemer H, Kalehzan BM, Schatzberg AF (2000). 24-Hour monitoring of cortisol and corticotropin secretion in psychotic and nonpsychotic major depression. Arch Gen Psychiatry 57: 755-760.

Raadsheer FC, Hoogendijk WJ, Stam FC, Tilders FJ, Swaab DF (1994). Increased numbers of corticotropin-releasing hormone expressing neurons in the hypothalamic paraventricular nucleus of depressed patients. Neuroendocrinology 60: 436-444.

Rhodes ME, O’Toole SM, Czambel RK, Rubin RT (2001). Malefemale differences in rat hypothalamic-pituitary-adrenal axis responses to nicotine stimulation. Brain Res Bull 54: 681-688.

Rybakowski JK, Twardowska K (1999). The dexamethasone/ corticotropin-releasing hormone test in depression in bipolar and unipolar affective illness. J Psychiatr Res 33: 363-370.

Stokes PE, Stoll PM, Koslow SH et al (1984). Pretreatment DST and hypothalamic-pituitary-adrenocortical function in depressed patients and comparison groups. A multicenter study. Arch Gen Psychiatry 41: 257-267.

Swaab DF (1995). Ageing of the human hypothalamus. Horm Res 43: $8-11$.

Thomassin H, Flavin M, Espinas ML, Grange T (2001). Glucocorticoid-induced DNA demethylation and gene memory during development. EMBO J 20: 1974-1983.

Uhr M, Grauer MT (2003). abcblab P-glycoprotein is involved in the uptake of citalopram and trimipramine into the brain of mice. J Psychiatr Res 37: 179-185.

Uhr M, Steckler T, Yassouridis A, Holsboer F (2000). Penetration of amitriptyline, but not of fluoxetine, into brain is enhanced in mice with blood-brain barrier deficiency due to mdrla Pglycoprotein gene disruption. Neuropsychopharmacology 22: 380-387.

von Bardeleben U, Holsboer F (1991). Effect of age on the cortisol response to human corticotropin-releasing hormone in depressed patients pretreated with dexamethasone. Biol Psychiatry 29: $1042-1050$.

von Bardeleben U, Wiedemann K, Stalla GK, Muller OA, Holsboer F (1988). Exaggerated corticotrophic cell response to human corticotropin-releasing hormone in two patients during longterm carbamazepine treatment. Biol Psychiatry 24: 331-335.

Wang PW, Ketter TA (2002). Pharmacokinetics of mood stabilizers and new anticonvulsants. Psychopharmacol Bull 36: 44-66.

Wittchen HU, Knauper B, Kessler RC (1994). Lifetime risk of depression. Br J Psychiatry 26(Suppl): 16-22.

Zobel AW, Nickel T, Sonntag A, Uhr M, Holsboer F, Ising M (2001). Cortisol response in the combined dexamethasone/CRH test as predictor of relapse in patients with remitted depression. A prospective study. J Psychiatr Res 35: 83-94.

Zobel AW, Yassouridis A, Frieboes RM, Holsboer F (1999). Prediction of medium-term outcome by cortisol response to the combined dexamethasone-CRH test in patients with remitted depression. Am J Psychiatry 156: 949-951. 